\title{
Miguel Servet (1511-1553) y la geografía de su tiempo
}

\author{
JoAquín BosQue MAUREL *
}

\section{LA FIGURA}

La figura del aragonés Miguel Servet es clave en la historia del pensamiento español del siglo XVI. Por razones vitales aunque relacionadas con sus preocupaciones ideológicas, que hicieron de él un transterrado la mayor parte de su vida, mantuvo una actividad profesional varia y plural como publicista -teólogo, profesor, geógrafo, astrólogo- y, en especial como médico, profesión que inició en Francia y que le permitió subsistir en este país, su residencia fundamental fuera de España. En su pluralidad como publicista, merece señalarse su empeño y su trabajo en la edición de la Geografía de Ptolomeo, que sin duda le ha concedido un lugar relevante en la historia de los estudios geográficos y, sobre todo, en la del Renacimiento. Aunque debe recalcarse que su preocupación geográfica tuvo una importancia menor en el conjunto de la existencia material y espiritual del Miguel Villanovano o de Villanueva, seudónimo que Servet utilizó durante mucho tiempo durante sus años en Francia por motivos de seguridad personal ante su difícil situación respecto a la Inquisición tanto católica -española y francesa- como protestante, la calvinista en concreto, que le condujo a la muerte en la hoguera.

^ Universidad Complutense de Madrid. 


\section{Miguel Servet y la Geografía de Claudio Ptolomeo}

La primera edición de Ptolomeo llevada a cabo por Servet tiene por fecha 1535. Miguel de Villanueva, como entonces se hacía llamar el aragonés y que es el nombre con que se publica esta primera versión, tenía en aquel momento veintitrés $\mathrm{o}$, como mucho, veinticinco años: la fecha de su nacimiento no es segura, nació entre 1509 y 1511, según Baiton (1972), o en 1511, como asegura Alcalá (1980). La publicación se hace en Lyon por encargo de la casa editorial de los hermanos Melchor y Gaspar Trechsel y tiene por título Claudii Ptolemaei Alexandrini Geographicae enarrationis Libri Octo ex Bilibaldi Pirckeymheri tralatione sed Graeca \& prisca exemplaria à Michële Villanovano iam primum recogniti. Adiecta insuper ab eodem scholia, quibus exoleta urbium nomina ad nostri seculi more exponentur... Lugduni, ex officina Melchoris et Gasparis Trechsel fratrum . M.D.XXXV. Una segunda edición, en parte corregida y actualizada, se publicó con similares características internas, idéntico encabezamiento y los mismos editores, los hermanos Trechsel, seis años más tarde en la no muy alejada ciudad de Vienne del Delfinado (1541).

Miguel Servet, durante un periodo de tiempo de su adolescencia -1525 a 1528-, acompañó como paje y secretario a Juan de Quintana, miembro de las Cortes de Aragón y un clérigo muy próximo al Monasterio oscense de Montearagón, a varias comisiones en España ordenadas por el Emperador Carlos V, incluida una visita a la Alpujarra. Hacia 1528 fue enviado por su padre a seguir los estudios de Derecho en la Universidad de Toulouse, iniciando así una estancia al norte de los Pirineos que en la práctica nunca abandonó hasta su muerte en la helvética Ginebra. Desde Toulouse, tras apenas dos años de estudios, acompañó al mismo Quintana a la coronación imperial en Bolonia y, enseguida, a la Dieta de Augsburgo (1530), uno de los momentos claves de los intentos de conciliación con el naciente luteranismo enfrentado con Roma.

En ese tiempo, pese a su juventud, Servet había adquirido una extraordinaria formación intelectual; conocía perfectamente el hebreo, el griego y el latín, aparte el castellano, su idioma natal, y el francés en el que acababa de iniciarse, $y$ no menos toda la literatura relacionada con la cultura $y$, sobre todo, la teología cristiana, en plena discusión tras la exposición en 1517 en la puerta de la catedral de Wittenberg de las noventa y cinco tesis de Martín Lutero. Bainton llega a afirmar, "Era... asombrosa la amplitud de sus lecturas cuando tenía tan sólo dieciocho o diecinueve años . Cita (en sus primeras publicaciones) a ... Ricardo de San Victor, Occam, Holcot, D'Ailly, 
Gregorio de Rímini, Major "(1973, 48). Y además, conocía -o leyó muy pronto- las obras de Erasmo de Rótterdam, de los hermanos Alfonso y Juan de Valdés, de Melanchton, de Ecolampadio, entre otros, y conocía y estudiaba con inteligencia y profundidad los textos bíblicos en sus lenguas originarias.

Fruto de esas lecturas y de su tremenda inquietud espiritual y religiosa serán sus primeros escritos, De Trinitatis Erroribus y Diálogos sobre la Trinidad, dos obras publicadas en Hagenau, cerca de Estrasburgo, en 1531 y 1532. Sus muy radicales planteamientos para su tiempo del misterio de la Trinidad dieron lugar a un tremendo escándalo en toda Europa y a que, en el orbe cristiano de entonces, tanto católico como protestante, Servet fuese calificado de hereje, condenado como tal y perseguido con saña; tanto la Inquisición aragonesa como la francesa dictaron orden de búsqueda y captura contra él y prohibieron sus escritos. Desde entonces Miguel ocultó su nombre -"Michaelem Serveto, alias Revés, ab Aragonia Hispanum"-, con el que había firmado con orgullo, dice Alcalá (1980), las dos obras causa del escándalo, amparándose en el seudónimo de Michéle de Villeneuve - Michele Villanovano- que conservó hasta poco antes de morir, y con el que aparecerán todos sus posteriores escritos, incluso las ediciones de la Geografía de Ptolomeo. Escritos que contrastan con su modus vivendi esencial, la medicina, que estudió en Paris y Montpellier, y que mantuvo hasta su muerte.

La ya excelente formación filosófica y lingüística de Servet cuando llega a Lyon parece justificar el encargo de los hermanos Trechsel, con los que comenzó a trabajar como corrector de pruebas, de preparar la edición de la Geografía de Ptolomeo. Este, una de las grandes figuras de la ciencia geográfica grecolatina, fue director de la Biblioteca de Alejandría, donde vivió y trabajó entre los años 127 y 150 después de Cristo. En ella, con sus espléndidos fondos, luego desaparecidos por el incendio que la destruyó tras la ocupación musulmana (641), llevó a cabo su importante labor científica, fundamentada por dos escritos básicos, la Astronomía o Mathematiké Sintaxis, más conocida por el nombre árabe de Almagesto, que le convirtió en el gran astrónomo de su tiempo, y la Geographiké Uphegesis (Guía de Geografía), motivo de haber llegado a ser el modelo de geógrafo, real y virtual, desde la Antigüedad hasta la revolución científica del último Renacimiento.

Ptolomeo, famoso en el Imperio romano entre otros geógrafos anteriores y posteriores, como Eratóstenes (276-194 a. de J.C), Hiparco de Nicea (siglo II a. de J.C.), Estrabón ( 60 a. de J.C.- 20 d. de J.C), Marino de Tiro (siglo II d. 
de J.C.), fue más un mito que una realidad a lo largo de la Edad Media, en la que sólo se conoció parte de su obra y, en especial, la Astronomía, a través de las traducciones árabes que la popularizaron con el título ya citado de Almagesto y que, a partir del siglo XII, dieron paso a numerosas versiones latinas y castellanas fruto, entre otras, de la Ilamada Escuela de Traductores de Toledo, un eslabón básico en el conocimiento de muchos de los textos griegos y latinos generalizados desde entonces en el resto de Europa (J. Vernet, 1974).

En el caso de la Ceografía de Ptolomeo, aparte de unos nombres, Claudio Ptolomeo o Tolomeo, el Alejandrino, y algunos datos y referencias dispersos del vasto contenido de los ocho libros que se le atribuyen, su obra total permaneció en una curiosa oscuridad durante el transcurso de la Edad Media y sólo parece haber sido un documento relevante en el Imperio bizantino, donde se conservó - existen cincuenta y dos manuscritos bizantinos de la Geografía - hasta finales del siglo XIV. Juan Vernet en sus diferentes trabajos sobre la transferencia por los árabes de la ciencia clásica a Italia y España y, luego, a Europa central, no hace mención de la Geografía en tanto que, insiste, la Astronomía, el Almagesto, fue objeto de numerosas traducciones al árabe y de este al latín, como la de Gerardo de Crémona, hecha en España (1175), y también directas del griego al latín, por ejemplo, una siciliana anterior (1160), aparte otras aparecidas en los siglos XIII y XIV (J. Vernet, 1974).

No obstante, aunque no existe noticia alguna de una traducción medieval de la Geografía al latín ni a ninguno de los otros idiomas europeos, no fue esta obra desconocida del mundo musulmán, ya que había sido traducida al árabe en el siglo IX, en pleno esplendor del Califato abassida. Incluso, algún geógrafo musulmán, como Ibn Said el Magrebí, de Alcalá la Real (Jaén), escribió, en el siglo XIII, una compilación de la Geografía de Ptolomeo que tituló Extensión de la tierra en su longitud y latitud (E. Bullón, 1929).

Europa descubre la Geografía de Ptolomeo a finales del siglo XIV. En 1396, el erudito bizantino Manuel Crisoloras abrió en Florencia una cátedra de griego que creó una brillante legión de discípulos con los cuales inició la traducción y publicación de algunos de los textos más distinguidos de la cultura helénica. Uno de esos seguidores, Giacomo d'Angelo, tradujo al latín los ocho libros de la Geografía de Tolomeo, que dedicó al Papa Alejandro V hacia 1410, aunque no latiniza los numerosos topónimos de la treintena de mapas, que no siempre seguían a los ocho libros que componían -y componen- la obra tolemaica. Una cartografía que se ha discutido mucho sobre su pertenencia al mismo Ptolomeo; según E. Bullón no son del geógrafo alejandrino, habiendo sido trazados, de acuerdo con el pensamiento y los materiales del maestro, mucho más tarde por un tal Agathedemón en los talleres 
bizantinos de los siglos XIII y XIV, una idea bastante generalizada y que aparece en numerosos historiadores de la geografía (L. Gallois, 1890, C. Sanz, 1959, J. P. Arribas, 1976 y A. Hernando, 1992).

El conjunto de 28 cartas que, tradicionalmente, acompañaban -fuesen o no de Tolomeo -a los códices bizantinos, fueron copiados y sus topónimos traducidos al latín algo más tarde de 1410, en que se tradujo al latín la Geografía por los cartógrafos y copistas italianos L. Bonigsegni y F. de Lapacino. Enseguida, aunque con el título de Cosmografía que había sustituido al original de Geografía, su difusión fue considerable: se conservan treinta y ocho códicescopias de la misma, contando sólo los acompañados de la serie cartográfica. $\mathrm{Y}$, en fecha muy temprana y próxima al término de la traducción (1410), en 1412 o 1413, Pedro d'Ailly ya utiliza los datos del Ptolomeo de Giacomo d'Angelo en su Compendium Cosmographiae, complemento de su Imago Mundi (1480), una de las fuentes utilizadas por Colón en su proyecto de viaje a las Indias Orientales por Occidente (E. Bullón, 1929, y A. Melón, 1955).

En 1475, en Vicenza, la Geografía traducida por D'Angelo se imprimió por vez primera, aunque sin mapas, agregándose éstos, los de Bonigsegni y Lapacino, a los ocho libros en la segunda edición impresa de la traducción de D'Angelo (1477) (C. Sanz, 1959 y J. P. Arribas, 1976). A partir de aquí se inició un largo periodo de más de cien años en los que el dominio de la Geografía de Ptolomeo en el mundo científico y en la sociedad de su tiempo fue absoluto. "No se concebía la geografía fuera de las normas y contenido trazados por Tolomeo. Su Geografía era la geografía por antonomasia" (A. Melón, 1955), de tal modo que los autores de obras de contenido análogo respetaron la denominación de Geografía como propia del alejandrino, utilizando otras como Cosmografía, Mundo, Theatrum y Speculum.

En esos años la obra tolemaica es un auténtico bestseller, existiendo desde 1475, además de los códices-copia de la primera traducción, numerosas ediciones impresas. Tras las dos primeras de la traducción de D'Angelo, hasta la última de Gerardo Mercator -la primera es de 1578- fechada en 1730 en Ámsterdam, se publicaron un total de 57 ediciones de la Geografía tolemaica. De ellas, sólo la primera, de d'Angelo, y otras seis, de Johannes Werner (Nuremberg, 1514, Ingolstadt, 1533), de Erasmo (Basilea, 1535, Paris, 1546), de Pedro Núñez, (Lisboa, 1537) y Joannis Noviomagis (Colonia, 1540), se publicaron sin mapas. En las restantes versiones impresas, éstas tienen un numero de cartas distinto según los casos, ya que oscilan entre 27 , en las primeras, y 64, en las últimas (C. Sanz, 1959). Aparte de las dos ediciones de Miguel Servet, hay que destacar las de Martín Walsemüller (1513, 1520 y 1522)), Sebastián Munster (1540, 1541, 1542, 1545 y 1552), 
Bilibaldo Pirkheimer $(1525,1562$ y 1564) y Gerardo Mercator $(1578,1584$, 1602, 1605, 1618, 1624, 1698, 1704 y 1730). Esta última edición, con la que Mercator pretendió rendir homenaje al gran geógrafo y cartógrafo del siglo II después de Cristo, fue esencialmente una obra histórica y documental. En realidad, tanto el texto como la cartografía habían perdido actualidad y validez ante el conjunto de novedades - los grandes descubrimientos y la solución de los lógicos errores de los autores clásicos habidos durante los siglos XV y XVI- que aún habiendo sido introducidas en sus diversas ediciones renacentistas, a la larga no pudieron competir con las nuevas obras geográficas y cartográficas aparecidas a lo largo de los años Quinientos y, sobre todo, en su segunda mitad.

El número variable de los mapas que contienen las diferentes ediciones corresponde a la actualización introducida en las distintas versiones en función de los descubrimientos geográficos debidos, sobre todo, a españoles y portugueses en una época ( 1450-1650) que constituye el gran periodo de ampliación del mundo clásico por el reconocimiento del litoral africano y del sur de Asia, el descubrimiento y colonización de América y los viajes a través del océano Pacífico hasta las costas de orientales de Asia. Una realidad que comienza a recogerse a partir de 1507 en que la edición de Beneventano incluye seis mapas modernos y especialmente de la de 1513, en que Martín Waldseemüller, con 47 mapas, casi el doble de los estrictamente atribuibles a Tolomeo, cartografía el Nuevo Mundo y los territorios portugueses de Africa y Asia, además de ampliar y mejorar los tradicionalmente dedicados al Viejo Mundo y de origen tolemaico.

Solo así cabe explicar la larga vigencia de la cartografía del alejandrino tras su traducción al latín y las múltiples ediciones en este idioma y la aparición de versiones en los idiomas propios de los distintos países europeos desde la primera a un italiano versificado llevada a cabo por F. Berlingheri y publicada en Florencia en 1482, a la que siguieron otras al portugués de Pedro Núñez (Lisboa,1537), carente de mapas, al italiano de GirolamoRuscelli-Gastaldi (Venecia, 1561) y A. Maginus (Venecia, 1598) y, mucho más tarde, al francés de Halma (Paris, 1820) y al castellano por Carlos Sanz (Madrid, 1959). Es claro que, en algunas ocasiones, estas últimas versiones no pasaban de un mero hecho de curiosidad histórica y cultural completado en 1883 por la primera edición crítica greco-latina de C. Müller editada en Paris.

En todo caso, el eclipse de la Geografía de Ptolomeo se hace efectivo en 1570, momento de la salida a luz pública del Theatrum Orbis Terrarum de Abraham Oertel, más conocido con el nombre latinizado de Abraham 
Ortelius (1527-1598) (A. Melón, 1555). Editado por la casa Plotino, el Theatrum formaba un volumen en folio de setenta mapas distribuidos en cincuenta y tres hojas, grabados en cobre por Hogenberg, y que, a partir de un total de ochenta y siete cartógrafos cuyas obras habían sido copiadas o consultadas y un trabajo personal crítico y novedoso de Ortelius, constituía una imagen muy próxima y muy verídica de un mundo distinto al reflejado por Tolomeo y Servet y fruto de una técnica cartográfica libre de los agregados más o menos míticos y pintorescos que acompañaban la cartografía medieval y, en parte, la clásica. Asimismo, en Ortelius, la preocupación por un uso adecuado de las nuevas proyecciones y por la corrección constante de los errores y la insuficiente información propios de Ptolomeo, permitía una visión más segura e, incluso, más atractiva del momento en que se vivía. Su éxito es visible en las muchas ediciones del Theatrum aparecidas en sólo los últimos treinta años del siglo XVI: veintiuna en latín, dos en holandés, cinco en alemán, seis en francés, una en inglés, dos en italiano y cuatro en español. Únicamente la aparición definitiva del Atlas de Mercator en 1595, con su centenar de mapas que son el comienzo de la más moderna cartografía, desbanca tanto a Ortelio como a Ptolomeo, lo que no significa que la obra de estos dos últimos no siga presente en el mercado geográfico mundial durante al menos todo el siglo XVII (A. Melón, 1955).

\section{Las ediciones de la Geografía de Ptolomeo DE Miguel SERVET}

La capacidad de Servet, pese a su juventud, para desarrollar una excelente labor heurística era indudable, y no era menor su preparación lingüística. Sin embargo, cabe pensar que sus conocimientos geográficos y cartográficos no pasaban de los propios de un simple interesado en el conocimiento de los lugares y de su ubicación. Empero, también, era evidente su capacidad de trabajo y de entrega a un determinado objetivo científico bien justificada por sus anteriores estudios teológicos. En todo caso, la precisión de encontrar un trabajo que le permitiese subsistir fuera del apoyo de la familia y bajo los peligros inherentes a un transterrado amenazado por la justicia de su país natal, le obligaba a admitir cualquier clase de actividad que le permitiera subsistir.

El encargo de los Trechsel estuvo mediatizado por la obligación de partir de la edición del Ptolomeo preparada y publicada en 1525 por el humanista alemán Bilibaldo Pirckheimer, que, buen conocedor de las anteriores, 
las consideró tan plenas de fallos e incorrecciones que se sintió obligado a una edición superior a todas ellas en fidelidad y claridad, como en realidad lo fue en parte gracias a haber contado con la ayuda de Joannis Müller Regiomontano y haber utilizado en la impresión de sus mapas las mismas planchas de la edición de 1522 de M. Waldseemüller y L. Frisius, una edición considerada como el primer Atlas del mundo moderno (E. Bullón, 1929 y J. P. Arribas, 1976)).

Miguel Servet se adaptó perfectamente a la calidad del Ptolomeo base que tuvo que utilizar, pero desde el primer momento trató de mejorar y perfeccionar el texto de 1525, aunque exagera un tanto la bondad de su trabajo. En el prólogo y saludo que el mismo Servet dedica a sus lectores escribe: "En cuanto nos atañe, aplicamos todas las fuerzas y nervios a enmendar lo erróneo y explicar lo oscuro. Peligrosa labor por ambos lados, y por nadie hasta ahora acometida... De otros códices, ya griegos, ya latinos, y de la asidua lectura de otros lectores, restituimos lugares a millares, de los cuales será importante referir algunos centenares, para dar algún solaz a los que han de gustar de ello...". Y añade algo más adelante, "Callaré aquí los números de las longitudes y latitudes que enmendamos ... En el libro VIII que, si hemos de creer a Bilibaldo y a Erasmo, clamaba ser corregido más que todos los demás, añadimos unas notas... Después añadiremos unos escolios que harán la lectura más clara, suave y llana, los cuales cuánta ayuda han de prestar lo juzgarán quienes lo experimenten leyéndolos.... el que lea a nuestro Ptolomeo hallará esos nombres de ciudades mencionados por los antiguos... adaptados al lenguaje de nuestro tiempo, ...Y por intentar inclinar más los ánimos de los estudiantes a esta lectura, explicamos muchos vocablos de las ciudades en lengua vernácula por más fácil, con lo cual como que hablamos francés con los franceses, alemán con los alemanes, italiano con los italianos y español con los españoles, cuyas regiones todas vimos y cuyas lenguas hablamos en todas partes. ... Nos hemos esforzado cuanto hemos podido en dar los nombres de las ciudades en lengua vernácula a base de la autoridad de escritores, la experiencia propia y muy ciertas conjeturas." (A. Alcalá, 2004, 8-10).

No cabe duda que, de acuerdo con sus mismas palabras, "Servet, que sabía ver lejos y no gustaba de marchar por trillados senderos, comprendió que lo primero de todo para dar un texto legítimo era comparar entre sí los diversos manuscritos y depurar el verdadero sentido de los pasajes difíciles con ayuda de la erudición histórica y geográfica" (E. Bullón, 1929, 61). Y así lo hizo, introduciendo numerosas notas marginales e interlineales a fin de subsanar los errores de Pirckheimer y de las ediciones anteriores, correcciones que fueron recogidas -y también introducidas- en ediciones posteriores 
como las Sebastián Münster de 1540, 1542 y 1545, y en otros autores posteriores no seguidores directos de Ptolomeo como el mismo Ortelio. Además de la traducción y depuración del antiguo texto, Servet se preocupó, como el mismo dice, de señalar la correspondencia, con indudables errores propios de su tiempo, entre los antiguos topónimos citados por Ptolomeo y los propios existentes a mediados del siglo XVI. Para ello, utilizó las lenguas de los respectivos países que, Servet afirma, son tierras por él visitadas y cuyas lenguas le eran conocidas en mayor o menor medida.

Así la calidad y la validez de la edición servetiana es indudable, al menos en lo que se refiere a los ocho libros de la Ceografía de Ptolomeo, y en especial a los dos primeros dedicados a la teoría geográfica, a los instrumentos a utilizar por los geógrafos y a las bases sobre las que desarrollar la cartografía imprescindible derivada de esos estudios y también mantener las descripciones geográficas que acompañan a los mapas. En su prólogo, y sobre todo en sus notas y escolios, se refiere a los más de sesenta autores que, para su edición, ha consultado y utilizado. Realiza además, dice, una concienzuda labor de depuración y corrección de las tablas de topónimos y de sus latitudes y longitudes correspondientes, en torno a ocho mil, que constituyen el contenido de los seis libros siguientes, en realidad la gran aportación del Tolomeo del siglo II a la geografía del siglo XVI.

Topónimos a los que, a menudo, Miguel Servet añadió comentarios históricos referidos a cada lugar y demostrativos de su extraordinaria erudición. "Si la ciudad mencionada por Tolomeo es Chalcis, nos dirá que en ella murió Aristóteles; ... si Aquino, no se olvidará de consignar que fue la patria de santo Tomás; ...y si se trata de Sinope, advertirá que es la patria y el sepulcro de Mitrídate" (E. Bullón. 1929, 93). Y nunca se olvidará de considerar los aspectos económicos o estratégicos de los países o ciudades como también, con menor frecuencia, algunas de las características del paisaje y los aspectos físicos de tales pueblos. Todo ello, advierte en su prólogo, con el propósito de que su lectura sea grata y pueda servir a sus posibles lectores.

\section{LA CARTOGRAFía PTOLEMÁICA EN LA EDICIÓN SERVETIANA Y SUS ESCOLIOS}

En su Ceografía, Servet concede un gran valor al conjunto cartográfico añadido como colofón. Las dos ediciones estuvieron acompañadas de 50 cartas, 27 antiguas, es decir correspondientes al texto originario tolemáico, y 23 modernas, añadidas a lo largo del siglo XVI y que contienen los frutos de

ESTUDIOS GEOGR., LXVI, 258, ENERO-JUNIO, 43-69, 2005. ISSN: 0014-1496 
los descubrimientos habidos en el transcurso de los siglos XV al XVI. No son ciertamente obra de Miguel Servet que se limita a reproducir los de Pirckheimer de 1525, lo mismo que muchos de la edición de este último proceden del álbum cartográfico de la impresa en Estrasburgo en 1513. Así mismo, el texto latino de D'Angelo había sido revisado ya por Mathias Ringman mientras que sus 47 mapas, de los cuales 20 son modernos, habían sido dibujados, al menos en parte, por Martín Waldsseemüller, llegando a un álbum considerado como el primer gran Atlas del mundo moderno. En todo caso, si no hay una aportación específica de Servet en este sentido sí señala muchos de los errores existentes lamentándose de no haber podido subsanarlos todos (E. Bullón, 1929, 107).

Las cincuenta cartas que forman el apéndice cartográfico, antiguas y modernas, cubren todo el espacio terrestre entonces mejor o peor conocido, incluido el resultado de los últimos descubrimientos allende el Atlántico. El primero es un mapa del mundo, del ecúmene, en el que en medio del actual Brasil aparece la palabra América y que recuerda mucho al de Waldseemüller de 1513. Sigue un conjunto de quince mapas dedicados a Europa y ordenados de occidente a oriente que se inicia con el correspondiente a Gran Bretaña e Irlanda, al que siguen los dedicados a Hispania y la Galia, los referentes a Germania en conjunto, más Suavia y Baviera, a Italia y a sus islas, Sicilia, Cerdeña y Córcega, y termina con tres correspondientes a la Hélade, los de Tesalia, Macedonia y Acadia, intercalando dos sobre Polonia y Hungría. A continuación se incluyen tres tablas acerca de Africa y doce de Asia donde se recogen los descubrimientos portugueses en las costas atlántica e índica, aparte uno monográfico acerca de Babilonia, Hircania y Media. Seguidamente se encuentra el referente al Océano occidental o la Tierra Nueva, América, y reaparecen cartas sobre Europa central, con tres regiones de Germania (Bohemia, Sajonia y Francia) más un tabla nueva de Hungría, Polonia, Prusia, Rusia y Valaquia, otra de Moscovia, una moderna sobre Bosnia, Servia, Eslavonia y Grecia, además de Tracia, que componen un gran fresco sobre la hoy península balcánica. Aparecen después los mapas, a menudo muy renovados, de las regiones del oeste y sur de Asia, Turquía y Arabia, Tierra Santa o Palestina, la India Superior y la Tartaria Mayor, las tierras del Gran Khan . Y se acaba el atlas con una tabla nueva acerca de la provincia del Rhin y otra "neotérica" de Creta o Candía. Un orden preestablecido y orientado sólo roto en principio por el interés de la inclusión de los conocimientos producidos en ese tiempo (J. Goyanes, 1935 y C. Sanz, 1959).

Complemento esencial de esta cartografía son sus escolios o comentarios y se conocen como un "Estudio reciente de las Regiones de Europa". 
Desde el discurso de Eloy Bullón en la Real Academia de la Historia pronunciado el 23 de diciembre de 1928 en su recepción como miembro de número de esa corporación, se ha insistido mucho en el interés y el valor que tienen los escolios que acompañan a los diferentes mapas recogidos $y$ que han llegado a considerarse como la aportación más importante y personal del heresiarca aragonés a la geografía de su tiempo. Así lo hace Eloy Bullón, que reproduce y comenta algunos de los comentarios en teoría obra de Miguel Villanovano, Miguel Servet.

Una afirmación, repetida por la mayor parte de los estudiosos españoles que se ocupan de él, y que tuvo confirmación implícita cuando, en 1935, el doctor J. Goyanes Capdevila tradujo y reprodujo la totalidad de estos escolios existentes en el dorso de los mapas que figuran en las dos ediciones de Servet. Y que ya habían sido objeto de comentarios a veces muy críticos por el Padre Flores en su España Sagrada (1747), mucho más tarde por Eliseo Reclús (El Hombre y la Tierra, 1905), y actualmente por Ángel Alcalá en su traducción y edición de las Obras completas de Miguel Servet (2004).

No obstante, Bullón, al referirse a estas descripciones afirma que "no son íntegramente de nuestro geógrafo" (pag. 111), y continúa, "lo que hizo el Villanovano fue revisar, añadir y mejorar las descripciones, que figuran ya en la edición de Pirckheimer de 1525, y que, sin embargo, no habían sido obra de éste, como el mismo Pirckheimer cuida de advertirlo al final de su libro" (p.111-112). Un hecho que el servetista Ángel Alcalá ha confirmado tras haber contrastado los textos de Servet con los de las ediciones anteriores de Pirckheimer y Waldseemüller, afirmando que las aportaciones originales de Servet pueden catalogarse en tres diferentes grupos: primero, una adaptación terminológica, en segundo lugar, diferentes notas marginales e interlineales a los siete primeros libros del Ptolomeo original y, finalmente, en contra de lo sostenido por la mayor parte de los comentaristas modernos desde Eliseo Reclús (J. P. Arribas, 1976, 18), algunas adiciones y correcciones -muchas menos de lo supuesto- a los escolios que acompañan los mapas del libro VIII , que denominará según Alcala (2004, 16), "Tradición reciente de las regiones de Europa por Miguel de Villanueva".

Estos escolios están casi estrictamente dedicados a los hombres, siendo poco frecuentes, aunque existen, los referentes a los hechos físicos, botánicos y zoológicos. Por ejemplo, entre estos últimos, resaltan algunos párrafos dedicados a España y Francia: "Francia es fecunda en abundancia de lluvias; los españoles usan mucho de aguas acanaladas, trayendo de muy lejos acequias de los grandes ríos. España no está, como Francia, fatigada por los 
vientos norteños y por los fríos. ... Del suelo francés casi ninguna parte está ociosa; en el español hay muchos lugares incultos y desiertos. La caza mayor y menor abunda más en Francia y muchos se alimentan de volátiles" (A. Alcalá, 2004, 20-22). En el primero de los escolios sobre Africa se señala "A la verdad, la máxima parte de ella está inculta, y o está cubierta de arenas estériles, o es desierto por el clima o está infectada de muchos y maléficos géneros de animales" y se insiste más adelante "Por el sur es muy desierta, a causa de los excesivos calores....Cría asimismo leones, pardales, cabras y monos que son sobremanera frecuentes en algunos lugares. $\mathrm{Y}$ hay jirafas y búfalos parecidos a los toros...Hay, además, dragones, hienas, puerco espines, carneros salvajes ...., panteras, cigüeñas, pigardos, avestruces, además de muchas especies de serpientes, las cerastas y el áspid" (Á. Alcalá, 2004, 44-45). Y es evidente que no falta una curiosa mezcla de realidad y fantasía.

Al hablar de Egipto parece recordar a Herodoto, "En Egipto nunca se vio llover, sino que la tierra misma es fecundada por la inundación del Nilo todos los años, después del solsticio de verano".(A. Alcalá, 2004, 47). Tampoco faltan en el apartado sobre Asia algunos comentarios en esta línea: "En esta tabla (Asia, IV) se incluyen dos partes de Arabia, a saber: la desértica y la fértil, pues Arabia es triple, ...la Pétrea, la Desértica y la Feliz... Y de la Desértica, sólo (se dirá) que es un yermo de maravillosa grandeza donde solo moran serpientes y bestias feroces" (A. Alcalá, 2004, 55). Conviene advertir que la mayor parte de estos comentarios, y en especial los dedicados a Asia y Africa, parecen poco investigados por Servet y son en gran medida, así lo dicen también Bullón (1929, 111-112) y Arribas Salaverri (1976, 19), una simple copia de los existentes en la edición de Pirckheimer de 1525.

Pero en todo momento resalta cierta preocupación en establecer comparaciones y contrastes, no sólo críticos en general, sino más aún irónico y, a veces, muy duros al resaltar los vicios y los defectos de los diferentes habitantes de los países cartografiados Fórmula de trabajo que le hizo a Reclús considerar a Servet, sin duda con mucho optimismo, el padre de la Geografía comparada (J. P. Arribas, 1976, 18).. Un planteamiento que se hace muy explícito en el paralelo entre España y Francia y al que Bullón (p. 116) califica de un "retrato poco halagüeño de los españoles de su época", aparte de transcribir en el apéndice $3^{\circ}$ de su Discurso el texto completo (De Hispana et eius ad Galliam comparatio) que aparece en el dorso del mapa antiguo de España de las dos ediciones de 1535 y 1545 . Inicia el contraste afirmando que" España es superada por Francia en abundancia de vino, grano y carnes; pero la vence en su bondad y sabor". Enfrenta a españoles y 
franceses, y dice, entre otras frases, "los franceses son más parlanchines; los españoles, más taciturnos, pues aprendieron a disimular mejor. Los franceses son alegres, animados, inclinados a banquetes, y huyen profundamente la hipocresía y la gravedad, que guardan los reconcentrados españoles. Son, pues, los españoles en los banquetes menos sociables, más ceremoniosos, afectando no sé qué severidad de la que los franceses no se cuidan". Y, enseguida, señala, "la lengua española es más grave, la francesa, más suave. Entre los españoles, los castellanos, pueblos dilatadísimos, la usan más elegante; en Francia apenas distinguirás qué ciudad habla el verdadero francés de manera que sea más noble y castizo que peculiar de ese lugar. Es también la lengua española más cercana al latín". Y unas líneas más adelante, añade "Es muy inquieto y rumiador de grandes cosas el ánimo de los españoles, que son de ingenio feliz, pero aprenden infelizmente. Semidoctos, se consideran ya doctos; muestran sabiduría mayor de la que tienen, por la simulación y una cierta verbosidad. ... Les gusta hablar en las academias más en lengua española que en latín y no dejan de tomar muchos vocablos de los moros" (A. Alcalá, 2004, 20-24).

Parece que, aún reproduciendo un texto anterior, Servet ha introducido en él su propia experiencia derivada de una presencia de varios años en Francia y también de saberse perseguido y extraño en su propio país (J. Bosque Maurel y F. Ortega Alba, 1995, 42-43). Este duro comentario, en el que existen muchas más consideraciones no menos ásperas, fue reproducido por Münster (1540) y provocó una respuesta muy agria del humanista portugués Damián de Goes, entonces residente en Lovaina, y que estaba preparando una descripción de España publicada en 1541 en la que incluyó un alegato rebatiendo las opiniones de Servet y Münster. Este último se disculpó refiriéndose a su fuente, el villanovense (E. Bullón, 122-123).

Quizás sea el comentario que acompaña al mapa del Nuevo Mundo y del Ilamado Océano Occidentalis el que ofrece una intervención más personal de Miguel Servet. Y ello aunque sea, en principio, una reproducción, con algunas variantes, del de Pirckheimer de 1525 y este, a su vez, copia del de 1513 de Waldseemüller, y en el que parece se recogen por primera vez los resultados de los primeros viajes de Colón y de otros navegantes españoles. Insiste Servet en el hecho del descubrimiento de ese Nuevo Mundo por Cristóbal Colón, "natione italus", y de la importancia de la intervención de los Reyes Católicos y de los marinos hispanos en sus viajes. En sus últimos párrafos, según Bullón pertenecientes en exclusiva al escritor español, y que Alcalá admite ha mofdificado en muchos detalles, se refiere a lo injusto del nombre de América dado a estas tierras -así aparece literalmente en el mapa de 
Waldsemüller de 1513 y en el de Servet - ya que la intervención de Américo Vespucio en esos viajes no era en ningún caso comparable a la de Colón $y$ el resto de los marinos españoles.

Colón, afirma Servet, fue el descubridor de un continente " y dejando allí algunos compañeros para custodio y posesión del Nuevo Orbe hallado por ellos, .... el mismo Colón con los demás en dos naves a España, donde, recibido con grandes honores por los reyes, fue saludado por todos como virrey, almirante y gobernador del dicho Nuevo Orbe...Y habiendo vuelto nuevamente al continente, descubrió otras muchas islas, las cuales dominan hoy muy felizmente los españoles. Y se equivocan grandemente los que pretenden que aquel continente se Ilame América, porque Américo fue a aqueIlas tierras mucho después de Colón, y no fue con los españoles, sino con los portugueses, y con ánimo de comerciar" (A. Alcalá, 2004, 77-78). Esta reivindicación de la presencia hispana había aparecido antes en el segundo escolio, el referente a España y su comparación con Francia, donde afirma "Son célebres los españoles en todo el orbe por sus navegaciones oceánicas para descubrir nuevas regiones, hacia el Mediodía, hasta los confines meridionales de África, fueron los primeros que dieron la vuelta al mundo; hasta Calcuta y otras islas de oriente, cuyo campo es peculiar a los portugueses o lusitanos. Hacia Occidente, los castellanos partieron en pos de una muchedumbre de islas, ricas en oro, llegando también al mismo continente de las Indias orientales, en el cual permanecen para civilizar más y más a los indios. Alcanzaron también noticias de las regiones que están bajo el polo austral" (A.Alcalá, 2004, 25)..

En todo caso, en principio, parecen predominar los textos prácticamente intocados procedentes de Pirckheimer. $Y$ en algunos casos, admitidos y transcritos por Servet sin ninguna reserva aparente, siendo, a menudo, expresamente mordaces gracias quizás al villanovense, en especial cuando se refiere a los países europeos. En el escolio sobre Alemania dice: "Hungría produce bueyes; Baviera, cerdos; Franconia, cebollas, nabos y regaliz; Suavia, meretrices; Bohemia, herejes; Baviera, ladrones; Suiza, carnífices y boyeros; Westfalia, embusteros, $y$, finalmente. toda Alemania y todo el norte, glotones y bebedores" (A.Alcal.a, 2004, 30). Y no menos cáusticos son los comentarios sobre los italianos. "Los vénetos... fingen perdonar las injurias, pero si alguna vez tienen ocasión, nadie se venga con más crueldad... Los milaneses, odiosos a los franceses, a los que a su vez odian... Su conversación es ruda, su lenguaje es precipitado, pero mucho más rudo y molesto es el de los piamonteses. En la guerra no sirven, como no sean muchos juntos... La orgullosa Roma, despojada del imperio de las gentes, 
fue hecha sede del Sumo Pontífice... Son los romanos celosos y vengan severísimamente los adulterios de las mujeres... Los napolitanos rechazan los consejos de todos. Son salvajes, locuaces, vengadores de las injurias y muy recordadores de los beneficios... Se burlan los napolitanos de los calabreses, los calabreses de los puglieses, de todos ellos los romanos... y aun de todos los demás mortales, se burlan los italianos, los desprecian y los Ilaman bárbaros, siendo ellos, sin embargo, presa, ya de los españoles, ya de los franceses, ya de los alemanes" (A. Alcalá, 2004, 35-36).

Evidentemente no fue Servet quien inventó todas estas puyas, ya existentes en las ediciones anteriores, que parece tienen mucho que ver con el creciente pensamiento protestante, y dan "la impresión de que le gustaban mucho" a Servet, lo que dadas sus experiencias y sus ideas críticas no era extraño (R. H. Bainton, 1973, 101-103). Su ideario teológico y religioso, directa o indirectamente, parece traslucirse con cierta frecuencia. "Son también los germanos propensos al culto de Dios, pero no abandonan fácilmente sus opiniones una vez imbuidas, ni pueden ser reducidos del cisma a la concordia. Al contrario, cada uno defiende su herejía con valor" A. Alcalá, 2004, 31). . Al describir a Bohemia, llega a decir "No hay ley alguna y no hay institución alguna más santa que otras: todas son lícitas. ... Al romano Pontífice lo reducen a igualdad en el orden (sagrado), y niegan que sea más augusto y venerable que los demás y afirman que entre él y los otros sacerdotes no hay diferencia alguna" (A. Alcala, 2004, 79) Parece así traslucirse una cierta tolerancia religiosa que, cuando trata De las costumbres de los árabes y de los prodigios de Arabia, le lleva a decir "Es maravilloso que los árabes hayan permanecido siempre libres entre los poderosísimos imperios de medos, persas, griegos y romanos y por nadie hayan sido dominados, y que hayan venido espontáneamente a la ley de Mahoma, en la que persisten" (A. Alcalá, 2004, 61).

En un caso concreto, esa admisión y posible revisión de los textos anteriores, fuesen más o menos veraces y respetuosos parece patente. Es el caso del aparecido sobre Palestina en la edición de 1535 y suprimido en la de 1541, y que fue utilizada por Calvino y sus enemigos en Ginebra como una afirmación herética contraria a la Biblia que exigía su castigo. En la Geografía preparada por el villanovense, la Tierra Santa, Palestina, no era la tierra de bienandanzas y prosperidades, abundante en leche y miel, de los textos sagrados, sino, según afirma, y de acuerdo con el testimonio de peregrinos y comerciantes, una región estéril, áspera e inculta. Y añadía, "De modo que se le puede llamar "tierra prometida" sólo en el sentido de que fue prometida pero no en el de que ofreciera promesa alguna" (J. Goyanes, 1935 ). Una versión algo 
diferente es la de A. Alcalá $(2004,94)$, aunque en el fondo coinciden: "Por lo cual, a la Tierra Prometida Ilámala esperada, pero no la alabes en tu propia lengua". Una admisión que ya no mantuvo Münster, afín tantas veces a Servet, y que a este último contribuyó a llevarle a la hoguera.(R.H. Bainton, 1973, 104-105).

\section{El Pensamiento geográfico de Claudio Ptolomeo y Miguel SERVET}

El Renacimiento significó la recuperación de la cultura del mundo clásico iniciada por los griegos y mantenida y desarrollada por Roma. Una recuperación que tuvo muy en cuenta la obra geográfica de cada momento, en muchos casos ligada a los avances de la historia $Y$, así, junto a la traducción y el seguimiento de Claudio Ptolomeo, la Geografía renacentista estudió, tradujo y comentó los trabajos de Estrabón (63 a. J.C.-19 d. J.C.), Pomponio Mela (s. I. d. J-C.) y los dos Plinios, el Viejo (23/24-79 d. J.C.) y el Joven (61114 d. J.C.i), autores citados por el mismo Miguel Servet en su Prólogo a Tolomeo como anteriores a este último, aunque considerándolos inferiores en "el arte geográfico" (A. Alcalá, 2004, 7).

Los 17 libros de la Geografía de Estrabón, escritos en griego posiblemente entre los años 29 y 7 antes de Jesucristo, se tradujeron al latín hacia 1454 y fueron impresos en Roma el año 1471, la primera edición moderna de la Chorographia de Pomponio Mela apareció en Milán en 1441, aunque fue mejorada por la de Basilea de 1522, y la Naturalis Historia de Cayus Plinius Secundus, de la que existen unos 200 manuscritos, dio lugar a varias ediciones de las que cabe mencionar una en Parma (1476), la de Roma de 1492 y otra, en Basilea, de 1525. Todas estas obras fueron bien conocidas y comentadas durante el Renacimiento y después, y solo en España fueron numerosas las referencias existentes entre los eruditos españoles contemporáneos de Miguel Servet, como Antonio de Nebrija (1444-1522), Fernán Núñez el Pinciano (1475-153), Hernán Pérez de Oliva (1494-1531), Ambrosio de Morales (1513-1591), Pedro de Esquivel (15 -1575), entre otros, $y$ desde entonces han sido obras sumamente utilizadas y muy generalizadas (A. García y Bellido, 1945 y 1947).

Unos geógrafos que fueron, sin duda, fuente de estudio en la Geografía del alejandrino y luego utilizados en las notas y escolios en la edición servetiana. Ptolomeo, además, como Servet después, recogió y hizo uso de las ideas de otros geógrafos, sobre todo griegos y menos romanos -Anaximandro 
(610-546 a. J.C.), Hecateo de Mileto (s. VI a. J.C.), Dicearco (310 a. J.C.), Eratóstenes (274-194 a. J.), antecesor de Ptolomeo en la Biblioteca de Alejandría, Hiparco de Nicea (siglo II a. J.C), Posidonio de Apamea (s. I. a. J. C.), Marino de Tiro (siglo II d. J.C.)-, de cuyas personalidades poco se sabe y cuyas obras nunca llegaron completas hasta nosotros salvo algunas ideas y diversos párrafos recogidos por sus contemporáneos, el mismo Tolomeo y antes por Estrabón (1980, 5-26) en sus respectivas Geografías. Su indudable peso fue reconocido muy pronto por la erudición renacentista; en 1498, escribía Antonio de Nebrija en su Introducción a la Cosmografía, " si quieres conocer las primeras nociones y elementos de los cosmógrafos te bastará este compendio; pero si deseas mayores adelantos, lee los libros que escribieron Estrabón, Plinio y Mela, y los que compusieron Tolomeo, Avieno, .."(E. Bullón, 1929, 35).

La ruina y desaparición del Imperio Romano de Occidente y su reparto y ocupación por los diversos pueblos bárbaros que lo habían invadido significó un profundo cambio cultural y el olvido y también la desaparición de buena parte de la literatura, científica o no, del mundo grecolatino. Una realidad que no excluyó la permanencia de su memoria y su prestigio y de numerosos intentos de recuperación de ese pasado del que un ejemplo memorable son las Etimologías de San Isidoro de Sevilla (550/557-636), vasto y sistemático repertorio de todo el saber humano de raíz grecolatina que fue leído y saqueado sin tregua durante toda la Edad Media (A. Melón, 1954).

Mientras se mantuvo vivo el Imperio Romano de Oriente, más tarde Imperio Bizantino, se conservó y estuvo vigente gran parte del legado de la Antigüedad clásica que fue transferido parcialmente al árabe durante el Califato abassida hasta mediados del siglo XI y, después, a través de países musulmanes como los implantados en la Península lbérica entre 711 y 1492. Cabe destacar a la Escuela de Traductores de Toledo, que lo trasladó al latín y a las lenguas de Europa Occidental facilitando su reincorporación a la cultura occidental. La caída de Constantinopla (1453) en poder de los turcos otomanos determinó un segundo y último trasvase de la cultura clásica, incluido el saber geográfico, a Occidente y el gran y definitivo desarrollo del Renacimiento con todas sus consecuencias y derivaciones.

En el campo de los estudios geográficos, "la concepción medieval del mundo y de la cultura adquiere con los principios del Cristianismo una expresión singular frente a la aceptada por los antiguos" (K. Kretschmer. 1930, 36). Convertida la Biblia en el libro básico de la fe y de la sabiduría, las noticias geográficas que se encontraban en las Sagradas Escrituras fueron especialmente examinadas, recopiladas y comentadas constituyendo la 
base en muchos casos del conocimiento del aspecto formal de la Tierra, y admitiendo sólo las enseñanzas de los antiguos mientras no estuviesen en contradicción con las opiniones bíblicas. Todo ello sin olvido de ciertas excepciones que fueron generalizándose a medida que, desde el siglo XIII, van Ilegando a Occidente algunas de las fuentes originales griegas, especialmente Aristóteles a través de la filosofía tomista

En paralelo, tiene lugar una importante ampliación del horizonte geográfico clásico gracias primero a los viajes por el Atlántico septentrional de los vikingos y de los monjes irlandeses en los siglos IX a XI, después de los árabes por el Ïndico y el norte de Africa, en las centurias VIII a XIV -Massudi (s.X), Ibn Idrisi (1100-1164), Abulfeda (1273-1331), Ibn Batutah (13021377) - y no menos de otros de origen europeo, italianos, flamencos y españoles -Giovanni Piano de Carpini (s. XII), Guillermo de Rubruk (s. XIII), Marco Polo (1255-1323) y Ruy González de Clavijo (1355?-1412)-, los de estos últimos facilitados por las Cruzadas y por la aparición de los pueblos mogoles en las fronteras orientales europeas a lo largo de los siglos XI al XIV. Y no cabe olvidar el profundo significado tecnológico de la primera penetración en el Atlántico, el Mare Tenebrosum, con la incorporación a Castilla y Portugal de las islas Canarias (1402), Madeira (1418) y Azores (1431), y el comienzo de los viajes siguiendo la costa africana hacia el sur.

Un conjunción de hechos que tendrá su culminación en el gran momento de los viajes de exploración mundial protagonizado por los marinos ibéricos -portugueses y españoles- entre comienzos del siglo XV y finales del XVI y su cenit en la expedición dirigida por Cristóbal Colón y su descubrimiento de un Nuevo Mundo en 1492. Etapa en la que la recuperación del pensamiento geográfico clásico y, en especial, la traducción al latín y la generalización de los escritos de Claudio Ptolomeo y de otros geógrafos de la antigüedad grecolatina ejerció un influjo decisivo en el proyecto y la ejecución de muchos de esos viajes, incluido el de Cristóbal Colón.

La tenacidad con que el genovés sostuvo hasta el último momento que las tierras descubiertas por él eran parte del continente asiático, las Indias orientales, tuvo mucho que ver con la polémica recogida por el mismo Ptolomeo con Marino de Tiro sobre la amplitud de este a oeste del ecúmene. Según este último geógrafo tal distancia era de 225 grados de un globo terrestre menor de lo que realmente es, y reducía a sólo 135 grados la anchura del Atlántico, es decir la supuesta distancia entre las islas Canarias, donde situaba el meridiano $0^{\circ}$, y el litoral asiático. Esta opinión fue considerada un error por Tolomeo que cifraba en 180 grados la distancia entre las costas atlánticas y reducía el ecúmene a otros tantos grados, una teoría

ESTUDIOS GEOGR., LXVI, 258, ENERO-JUNIO, 43-69, 2005. ISSN: 0014-1496 
también equivocada por no tener en cuenta la existencia de una América entonces desconocida y aceptar una Tierra inferior en tamaño a la realidad, ya que admitía la longitud de la circunferencia terrestre dada por Posidonio de 180.000 estadios, un tercio menor que la real, en lugar de los 252.000 estadios de Eratóstenes, solo un 1 por 100 inferior. La discordancia entre los dos geógrafos clásicos fue conocida al aparecer la versión latina del alejandrino y haber sido recogida por dos de las principales fuentes colombinas, la carta al rey de Portugal del florentino Paolo dal Pozzo Toscanelli (1474) y el Imago Mundi -impreso en 1480- de Pedro d'Ailly, afines ambos, como Colón, a Marino de Tiro. $Y$ también existente en los mapas y el globo terrestre de Martín Behaim . Y no fue la única idea tolemaica difundida durante el Renacimiento.

La Geografía de Tolomeo fue el último y más valioso, por su difusión y su contenido, modelo de Geografía General, según nuestra visión actual, del pensamiento geográfico clásico. Un modelo que se oponía, en Grecia y Roma, y así lo hace el alejandrino, a lo que hoy llamaríamos Geografía Regional, que tuvo su expresión más válida en la Geografía de Estrabón, y a la que Ptolomeo denomina Chorographia. Precisamente, la primera cuestión que trata Tolomeo en el libro I, es la diferencia entre Geografía y Corografía que, en el latín de Servet, dice: "La Geografía es una imitación del aspecto de una parte de la tierra conocida junto con las que casi universalmente le son anejas. Se diferencia de la Corografía, pues esta describe sus partes aun las menores....". Una oposición que Servet en sus notas marginales amplia: "Tres son las diferencias entre Geografía y Corografía. Primera, el corógrafo describe cada una de las partes, aun las más pequeñas, el geógrafo describe lo continuo. Así, los corógrafos pintan las aguas, los edificios, las torres,...Esto es, en la Corografía no se observa la proporción de cantidad del todo a las partes. Segunda diferencia, los accidentes de los lugares son considerados por sólo los corógrafos. Tercera, los corógrafos son pintores de lugares aislados". (A. Alcalá, 2004).

Establecida la diferencia entre Geografía y Corografía, la obra tolemáica pretendía esencialmente construir una imagen de conjunto de la Tierra conocida con las máximas garantías de un acercamiento a la realidad mediante una reunión fiable de los elementos mínimos imprescindibles, los lugares, tanto físicos como humanos, que conformaban la esfera terrestre de manera que pudieran conducir a su representación cartográfica . Por ello, a través del uso adecuado de la metodología existente en el siglo primero después de Jesucristo y partiendo de una cuadrícula de círculos máximos, los meridianos y el ecuador, y mínimos, los paralelos, idea que había recogido, 
según confiesa el mismo alejandrino, de Hiparco y Marino de Tiro, llegar a una proyección ortogonal cónica en la que existen veintiún paralelos entre el Ecuador y la isla de Thule $\left(63^{\circ}\right.$ Norte) y un meridiano cada $5^{\circ}$ en lugar de los $15^{\circ}$ de Marino.

En el espacio terrestre resultante, recurriendo a una información y unos cálculos matemáticos muy primitivos, pudo llegar al establecimiento de un total de 8.000 lugares con unas concretas coordenadas geográficas, latitud y longitud, que pudieran permitir trazar un mapa de la porción de la Tierra conocida entonces, en el siglo I de Jesucristo y que se limitaba a la zona templada, intermedia entre los polos y el ecuador, el ecúmene establecido.

Una lista de lugares cuyas coordenadas daban una imagen detallada pero sumamente grosera de la realidad geográfica, como era lógico dada el desconocimiento existente de una gran parte del globo terrestre y la insuficiencia de los medios de observación existentes. Ptolomeo se equivoca incluso en los lugares más conocidos y, según Arribas Salaverri $(1976,13)$, "sitúa, por ejemplo, Marsella a la misma latitud que Bizancio, y Babilonia, dos grados y medio demasiado al Norte", "legando a la posteridad una muy falsa imagen" del mundo conocido que facilitó muchos de los errores en que incurrieron los geógrafos y navegantes renacentistas.

Errores que no excluían una excelente preparación científica y, sobre todo, matemática para su tiempo, a causa de la exigencia de establecer con la máxima exactitud posible esos ocho millares de coordenadas geográficas, fundamento de su Geografía. Por ello, Ptolomeo afirmaba que "no se puede llamar geógrafo quien no es perito en matemática", un aserto corroborado por Servet en sus notas, y que facilitó los estudios tolemáicos sobre la órbita celeste - Sintaxis Astronómica, Almagesto - y le concedió su fama como astrónomo durante toda la Edad Media tanto entre los árabes como entre los cristianos europeos. En definitiva, señalaba el mismo alejandrino, "comparándola con el cielo, se conoce la tierra" (A. Alcalá, 2004).

Este planteamiento partía de aceptar la esfericidad de la Tierra como un hecho incontrovertible frente a la idea, muy extendida y popularizada en la Antigüedad por Anaximandro y los geógrafos jonios, de que nuestro planeta era un disco redondo que flotaba sobre un mar inmenso. La esfera o esferoide admitida por Claudio Ptolomeo como realidad terrestre se remontaba a los filósofos pitagórico del siglo VI a. J.C. y, recogida por Aristóteles (384322 a. J. C.), fue desarrollada por Dicearco, Eratóstenes, Marino de Tiro y, finalmente, Ptolomeo. La alternativa pasó a la Edad Media en la que, sin embargo, motivos religiosos hicieron prevalecer la teoría de que la Tierra tenía el aspecto de un disco, como se resalta más o menos claramente en 
los escritos de San Agustín y San Isidoro. Quizás esta fuese la razón del relativo olvido a lo largo de los siglos medios de la Geografía de Ptolomeo frente a la gran difusión de la Sintaxis Astronómica y, por tanto, a la general aceptación de la Tierra como centro del Universo, sostenida por Tolomeo en esta última obra.

Ya en el siglo XV, la traducción y las numerosas ediciones de Ptolomeo favorecieron un regreso generalizado a la teoría de la esfericidad terrestre que ya fue admitida y difundida a lo largo del siglo XV por Pedro d'Ailly, Toscanelli, Martín Behaim y, en general, por todos los geógrafos y navegantes europeos del Renacimiento, aunque se siguió elucubrando con mayor o menor profundidad y seguridad sobre el tamaño de la Tierra, la relación entre las partes ocupadas por el océano y la tierra firme, la existencia de las antípodas, la división de la litosfera en tres o cuatro partes o continentes, la doctrina de las zonas climáticas y los cinco círculos paralelos-ecuador, los dos trópicos y los dos círculos polares-y, por último, en la posición de la Tierra en el Universo, geocentrismo o heliocentrismo.

Los grandes descubrimientos oceánicos y la consiguiente construcción de una cartografía nueva tuvieron un papel relevante en el paso a unos nuevos planteamientos geográficos y al nacimiento de unos mapas modernos que oscureció la obra de Tolomeo. En este aspecto, cabe destacar el importante papel desempeñado por los navegantes y exploradores españoles y, en el ámbito científico, por la Casa de Contratación de Sevilla (1503), gracias a las numerosas acciones de sus Pilotos Mayores, unas geográficas - la Suma de Geografía de Martín Fernández de Enciso (1519), el Espejo de Navegantes de Alonso de Chaves (1538), la Descripción de las Indias Occidentales de Juan López de Velasco (1574) -, otras náuticas - el Arte de Navegar de Pedro de Medina (1542) y el Breve Compendio de la Esfera y del Arte de Navegar de Martín Cortés (1551) - y, finalmente, cartográficas, el Padrón Real ordenado por el rey Fernando I (1508), el Islario General de todas las islas del mundo de Alonso de Santa Cruz (1542) (G. de Reparaz, 1943, y M. Cuesta Domingo, 1992). Todo un conjunto de aportaciones que, traducidas en muchos casos y repetidas veces al inglés, al francés y al italiano en pleno siglo XVI, ha llevado a afirmar que "Europa aprendió a navegar en libros españoles" (J. Guillén Tato, 1943).

Y no puede obviarse que las preocupaciones astronómicas tolemáicas -geocéntricas, con la Tierra como centro del Universo- fueron plenamente superadas con la publicación, en 1543, por el polaco Nicolás Copérnico, de su De revolutionibus orbium celestium que certificó, no sin discusión, la existencia de un sistema celeste heliocéntrico, ya anunciado por Aristarco 
de Samos en el siglo III antes de Cristo, con el Sol como centro y los planetas girando en torno suyo, una teoría ratificada y mejorada algo después por el alemán Johann Kepler (1609) y el italiano Galileo Galilei (1616), tras el olvido del planteamiento mixto del danés Tycho Brahe (1598).

Comenzó así a formarse un "corpus" geográfico que, con el mejor conocimiento de la superficie terrestre gracias a los descubrimientos y a los relatos de viaje y los estudios científicos por ellos provocados, fueron eliminando muchos de los errores y equívocos de los geógrafos anteriores, grecolatinos y medievales, produciendo no sólo una cartografía más veraz y exacta sino también una visión de la Tierra más acorde con la realidad sino también mejor comprendida y que trataba de llegar a su explicación. Todo ello de acuerdo con la extensión de la razón como base de conocimiento y la generalización del análisis racional de los hechos y de sus causas y resultados que fue predominando como método de estudio hasta la revolución científica iniciada en el siglo XVII a partir del pensamiento de Francis Bacon (1561-1626), Baruch Spinoza (1632-1677), Renato Descartes (1596-1650) e Inmanuel Kant (1724-1804), filósofo pero también geógrafo (J. M $M^{a}$ López Piñero, 1989,. Cl. J. Glacken, 1996, y M. Álvarez Gómez, 2004).

Nació entonces toda una literatura geográfica más científica y muy preocupada por la sistematización de las relaciones existentes entre las diversas partes y divisiones de la Tierra, como también entre el medio ambiente y el hombre. Y que pudo tener su inicio en la Cosmographia Universalis de Sebastián Munster (1545), una "descripción del mundo y todo lo que hay en este, (que) revela los secretos ocultos de la Sagrada Escritura, así como las de una sabia y juiciosa Naturaleza (y ya) da muestra de una notable conciencia del cambio del medio como parte de la historia cultural (contrastando, por ejemplo), el progreso histórico de Alemania con el deterioro en el medio de Tierra Santa, (aunque) no aporta explicaciones" (Cl. J. Glacken, 1996, 339). Una obra, la de Munster, aun muy simple, y que tiene su confirmación y su ampliación en el Theatrum Orbis Terrarum de Abraham Ortelius (1570) y en el Atlas sive Cosmographicae Meditationes de Gerardo Mercator (1595), aportaciones que renuevan a fondo la cartografía existente tanto en sus proyecciones como en la transcripción crítica de los lugares aunque sin olvidar y valorando muy positivamente la aportación de Ptolomeo (N. Broc, 1986).

A ella, pudiera añadirse también la Historia Natural y Moral de Indias (1590) del Padre José de Acosta (1540-1600) que afirma, al referirse a su propósito e intenciones, "hasta ahora no he visto autor que trate de declarar las causas de tales novedades y extrañezas de naturaleza (de las Indias Occidentales) ni que haga discurso e inquisición en esta parte; ni tampoco

ESTUDIOS GEOGR., LXVI, 258, ENERO-JUNIO, 43-69, 2005. ISSN: 0014-1496 
he topado libro cuyo argumento sean los hechos e historia de los mismos indios, antiguos y naturales habitadores del nuevo orbe" ( $)$. Bosque Maurel y F. Ortega Alba, 1995, 45). Y, no menos, un conjunto de obras como La Grandeza de las Ciudades (1588), De la Razón de Estado (1589) y las Relaciones Universales (1591) de Giovanni Botero (1544-1617) que, tras construir uno de los primeros análisis urbanos existentes, al plantearse la educación de un príncipe, insistirá en la importancia de la situación geográfica, haciendo hincapié en la superior influencia de los climas templados, en el análisis de la relación entre la religión y el clima y en los potenciales logros humanos, como el contacto cultural, el crecimiento de la población y su relación con las ciudades, enfermedades y recursos, dando pie a una primera aproximación al determinismo geográfico (M. de Terán, 1957, M. Quaini, 1981, 197-208 y Cl. J. Glacken, 1996, 342-344).

Un conjunto de planteamientos no constreñidos a los tres autores anteriores y que, con sus muchas limitaciones, aproximaron a los geógrafos del Renacimiento a muchos de los grandes problemas hoy considerados por la Geografía. Más adelante, alcanzaron una primera estructuración formal en la Geographia Generalis (1650) de Bernardo Varenio (1622-1650), una obra de originalidad indudable y en la que la huella de las ideas y concepciones de Copérnico y Galileo, así como de Bacon y Descartes, es considerable y clara $(\mathrm{H}$. Capel, 1974). Y recibiendo un primario y decisivo tratamiento científico por Alejandro de Humboldt (1769-1859), el "padre de la geografía", es singular el nivel de expresión científico-geográfica de los principios y pensamientos que también, entre Varenio y Humboldt, fueron objeto de una cuidadosa atención en la cátedra de Geografía ejercida por Kant en Koenisberg durante la segunda mitad del siglo XVII (M. Álvarez Gómez, 2004).

En todo caso, en el Renacimiento, la Geografía adquiere pleno valor político y social, amén de poder ser útil y práctica. El mismo Servet, en su preámbulo a la edición de Tolomeo de 1541, afirma: " En verdad es conveniente que los príncipes que gobiernan el mundo conozcan la Tierra y también quienes les sirven, especialmente cuando son enviados como embajadores a sus varias partes... Añádase el placer mismo de saber, con el cual se adorna el entendimiento y se modera el alma; de otro modo a manera de carneros erraremos por el desierto sin ninguna razón cierta de nuestra vida" (A. Alcalá, 2004, 15). Una frase que podría ser aceptada y apropiada por cualquiera de aquellos geógrafos que actualmente consideran a la geografía como una ciencia aplicada. Aunque, en muchos momentos, espuriamente, como un instrumento del poder en el que no siempre encuentra un puesto el común de las gentes (J. Bosque Maurel, 1996 y 1981). 
Se podría así admitir que, tras el reconocimiento de Ptolomeo en los siglos XV y XVI, incluidos sus diversos editores, con Miguel Servet en principio, y su declive en el Renacimiento, la Geografía, tanto en su parte general, debido a una nueva visión de lo que debía ser el conocimiento de la Tierra aunque con centro en el Hombre, como no menos en sus aspectos regionales, en sus escolios a los países y regiones cartografiados, con casi toda seguridad no redactados por Ptolomeo pero quizás si inspirados por su texto inicial, el "modernismo" en su sentido más amplio contagia e inspira la ciencia geográfica hasta su institucionalización en el siglo XIX., convirtiéndose así en un capítulo esencial en la "modernidad" hasta hace poco tiempo dominante pero todavía presente (T. Unwin, 1992)

Unas palabras del geógrafo brasileño Milton podría ser digno colofón a una geografía que comenzó a ser "nueva", "moderna", én pleno siglo XVI, con la revolución renacentista, creadora del Estado e iniciadora del Territorio como globalidad mundial. "Hoy, la naturaleza es histórica...inclusive el llamado "medio ambiente". Su valor "local" es relativo o, en todo caso, relativizado. Antes, era el Estado, en último término quien definía los lugares - de Colbert a Golberg - dos nombres paradigmáticos de la subordinación del Territorio al Estado. El territorio era la base, el fundamento del Estado-Nación que, al mismo tiempo, lo moldeaba. Hoy, viviendo una dialéctica del mundo concreto, evolucionamos de la noción, tornada antigua, de Estado territorial a la noción postmoderna de la "transnacionalización" del Territorio" (M. Santos, 1994, 15).

\section{REFERENCIAS BIBLIOGRÁFICAS}

AlCalÁ, A. (1972): "Nuestra deuda con Servet". Revista de Occidente, 113-114, pp. 233-260.

ALCALÁ, A. (1978): Servet en su tiempo y en el nuestro: el nuevo florecer del servetismo. Villanueva de Sijena, Instituto de Estudios Sijenenses "Miguel Servet", 63 Págs.

AlCalÁ, A. (s.a.): Miguel Servet. Publicación 80-67. Zaragoza, Caja de Ahorros de la Inmaculada de Aragón, 94 Págs.

Arribas SalaverRI, J. P. (1976): Miguel Servet, geógrafo, astrónomo y astrólogo. Homenaje nacional al ilustre sabio en Villanueva de Sijena. Villanueva de Sijena, Ayuntamiento y Diputación Provincial de Huesca, 71 Págs.

BAINTON, R. h. (1973): Servet, el hereje perseguido. Traducción de A. Alcalá. Ensayistas, 96. Madrid, Taurus, 303 Págs.

BARÓn, J. (1970): Miguel Servet. Su vida y su obra. Madrid Espasa - Calpe,

Bosque Maurel, J. (1966): "En torno a las posibilidades de aplicación de la Geografía". Homenaje al Excmo Sr. D. Amando Melón y Ruiz de Gordejuela. Madrid - Zaragoza, Instituto Juan Sebastián Elcano, pp- 203-214. 
Bosque Maurel, J. (1981): "Posibilidades de aplicación de la Geografía en España". I Coloquio Ibérico de Geografía. Salamanca, 1976. Universidad de Salamanca, 1981, pp. 35-45.

Bosque Maurel, J. y Ortega Alba, F. (1995): “Claudio Tolomeo (aprox. 90-168 d. J.C.) y Miguel Servet (1509-/151-1553)", pp. 40-43., en Comentarios de textos geográficos (Historia y crítica del pensamiento geográfico.). Colección "Prácticas de Geografía humana", 6. Barcelona, Oikos-tau, 179 págs.

BOWEN, M. (1981): Empiricism and Geographical Thought. Cambridge Geographical Studies 15. Cambridge, The University Pres, 351 Págs.

Broc, N. (1986): La Géographie de la Renaissance, 1420-1620. París, CNRS, 258 págs.

Bullón, E. (1929): Miguel Sevet y la Geografía del Renacimiento. Madrid, Librería General de Victoriano Suárez, 207 Págs.

CAPEL, H. (1974): "La personalidad geográfica de Varenio", en VARENIO, Geografía General (1650), Barcelona, Ediciones de la Universidad, pp. 9-84.

CAPEL, H. (1981): Filosofía y ciencia en la Geografía contemporánea. Una introducción a la Geografía. Barcelona, Barcanova, 511 Págs.

CUESTA DOMINGO, M. (1992): "'Tierra nueva y cielo nuevo'. Navegación, geografía y mundo nuevo". Boletín Real Sociedad Geográfica, CXXVIII, pp. 13-37.

DaINVILLE, F. de (1969): La géographie et les humanistes. Géneve, Slatkine Repart, XVII , 562 Págs.

Estrabón (1980): Geografía. Prolegómenos. Traducción y notas de I. Granero. Introducción por A. A. Rojo. Madrid, Aguilar, LVI y 477 págs.

GarCía y Bellido, A. ( 1945): España y los españoles hace dos mil años según la Geografía de Strábon. Colección Austral, 515. Madrid, Espasa Calpe, 307 págs.

García y Bellido, A. (1947): La España del siglo primero de nuestra era según P. Mela y C. Plinio. Colección Austral, 744. Madrid, Espasa Calpe, 302 págs.

GLACKEN, Cl. J. (1996): Huellas en la playa de Rodas. Naturaleza y cultura en el pensamiento occidental desde la Antigüedad hasta finales del siglo XVIII. Prólogo de Horacio Capel. Colección "La estrellas polar". Barcelona, Ediciones del Serbal, 729 págs.

Goyanes, CAPDEVILA, J. (1935): Biografía de Miguel Servet. Biblioteca Clásica de la Medicina Española, Madrid, Cosano, XII.

GoYANES CAPDEVILA, J. (1935): “Descripciones geográficas del estado moderno de las regiones en la Geografía de Claudio Ptolomeo Alejandrino por Miguel Villanovano (Miguel Servet)", en Goyanes Capdevila, J. (1935), Biografía de Miguel Servet. Madrid, Cosano, XII, pp.

GuilLÉN TATO, J. (1943): "Europa aprendió a navegar en libros españoles"

Hernando, A. (1992): "La Geografía de Ptolomeo y los primeros mapas. de España". Boletín Real Sociedad Geográfica, CXXVIII, pp. 93-123.

KRESTSCHMER, K. (1930): Historia de la Geografía. Traducción y notas de L. Martín Echeverría. Colección Labor, VII. Geografía, 56. Barcelona-Buenos Aires, Editorial Labor, S.A., 200 Págs., XVI láminas y 3 mapas desplegables.

López Piñero, J.M., Navarro, V. y Portela, E. (1989): La Revolución Científica. Biblioteca Histórica 16, $\mathrm{n}^{\circ}$ 6, Madrid, Historia 16, 219 págs.

Melón y Ruiz de Gordejuela, A. (1955): "Ocaso de la Geografía clásica". Rev. Arbor, 114, pp. 193-215.

Melón y Ruiz de Ordejuela, A. (1954): "La etapa isidoriana en la Geografía Medieval". Arbor, 103-104, pp. 456-467.

Menéndez y Pelayo, M. (1947): Historia de los Heterodoxos españoles. Santander, Edit. Aldus, III,

QUAINI, M. (1981): La construcción de la geografía humana. Oikos-sup /geografía 1, Barcelona, Oikos-tau, 245 págs. 
Reparaz, G. de (1943): "Historia de la geografía de España", en J. Gavira, España, La tierra. El Hombre. El Arte. Barcelona, Editorial Alberto Martín, I. pp. 9-134.

Rey PAStOR, J. (1945): La ciencia y la técnica en el descubrimiento de América. Colección Austral, 301. Buenos Aires, Espasa Calpe Argentina, 176 págs.

SANTOS, M. (1994): "El retorno del territorio", en Territorio, Globalizacâo e Fragmentaçâo, Sâo Paulo, Hucitec, pp. 15-20.

SAnz, C. (1959): La Geografía de Ptolomeo (Universalis Cosmographia secundum Ptholemoei traditionem et Americo Vespucciabienunique lustrationes: Mapa Universal de 1507 (Martín Waldseemüller). Madrid, Librería General Victoriano Suárez,

Servet, Miguel (1980): Restitución del Cristianismo. Edición e Introducción de Ángel Alcalá. Madrid, Fundación Universitaria Española, 821 págs.

Servet, Miguel (2004 ¿): Obras Completas. III, Escritos científicos. Edición Ángel Alcalá. (en prensa).

UNWIN, T. (1992): El lugar de la Geografía. Madrid, Ediciones Cátedra, 342 págs.

VEGA Díaz, F. (1977): Propuesta para una interpretación antropobiográfica de Miguel Servet. (Mitificación, desmitificación y remitificación). Lérida, Instituto de Estudios Sijenenses "Miguel Servet", 76 págs.

Villanovano, M. (Miguel Servet) (1535 y 1541): Claudii Ptolomaei Alexadrini Geographicae enarrationis libri octo. $1^{\text {a }}$ edición, Lyon, Melchior et Gaspar Trecsel., y $2^{\text {a }}$ edición, Vienne y los mismos editores. En la Biblioteca Nacional (Madrid), existen 1 ejemplar de 1535 y 2 de 1541.

\title{
Resumen
}

La figura de Miguel Servet, esencial en la historia de los heterodoxos españoles y europeos del siglo XVI, alcanzó importante relieve en el estudio y la difusión de la Geografía clásica y en especial en el conocimiento de Claudio Ptolomeo y su Geografía. Asimismo, desempeñó un importante papel en la evolución de los estudios geográficos en el Renacimiento y sus particulares principios científicos. En su muerte en la hoguera por hereje, dictada por Calvino, sus comentarios geográficos tuvieron una cierta importancia.

Palabras clave: Miguel Servet. Historia de la Geografía. Claudio Tolomeo. Geografía del Renacimiento.

\begin{abstract}
Miguel Servet. Such a relevant figure in the study of $16 \mathrm{Th}$ century Spanish and European Heterodoxes, was also important in the study and difussion of Classical Geography, specifically in relation to Claudius Ptolomeus and his Geografia. He played as well a relevant role in the evolution of Geography in the Rennaissance and its peculiar scientific principles. His Geographic Comentaries influenced in Calvin's decision to order his death at the stake for his heretical ideas.
\end{abstract}

Key Words: Miguel Servet. Historry of Geography. Claudius Ptolomeo.. Geography of the Rennaissance. 


\section{Resumé}

La figure de Miguel Servet, essentielle dans l'histoire des hétérodoxes espagnols et européens du XVI siècle, a eu une grande importance dans l'étude et la diffusion de la Géographie classique et surtout dans la connaissance de Claude Ptolémée et sa Géographie. De même, il a joué un grand rôle dans l'évolution des études géographiques de la Renaissance et ses particuliers principes scientifiques. Ses commentaires géographiques ont eu une certaine influence sur la sentence à mort sur le bûcher par hérétique dictée par Calvin.

Mots clé: Miguel Servet. Histoire de la Géographie. Claude Ptolémée. Géographie de la Renaissance. 